\title{
O impacto do compartilhamento de informações na redução do efeito chicote na cadeia de abastecimento
}

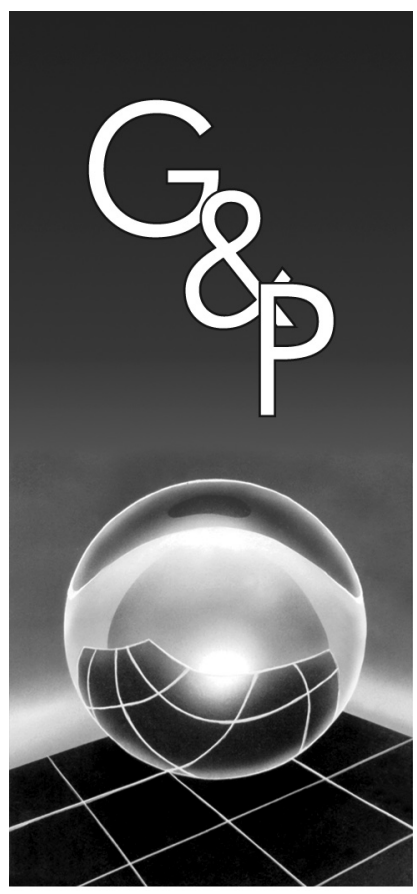

\author{
Leandro Callegari Coelho \\ Neimar Follmann \\ Carlos Manuel Taboada Rodriguez
}

Resumo

O objetivo deste artigo é destacar a importância do compartilhamento de dados em cadeias de suprimentos, como estratégia para reduzir o efeito chicote. Para isso é mostrado o que é esse efeito, suas causas, as formas como ele se apresenta e os meios para combatê-lo. Para facilitar o entendimento sobre os prejuízos causados devido à sua influência, é sugerido um cenário hipotético, em que os componentes de uma cadeia de abastecimento procuram alinhar sua oferta à demanda. Depois, com base numa pesquisa bibliográfica, apresenta-se a solução - o alinhamento estratégico e compartilhamento de dados -, o que cria a sinergia necessária para que a empresa e a rede desenvolvam sua vantagem competitiva. E por fim, para dar suporte à solução mostrada, criou-se um indicador com base em uma cadeia de suprimentos simulada diversas vezes em sala de aula, através de um software, o que veio comprovar os efeitos positivos do compartilhamento de dados.

Palavras-chave: Efeito chicote. Gestão da cadeia de abastecimento. Vantagem competitiva. Indicador de efeito chicote.

\section{Introdução}

O desempenho logístico tem, atualmente, forte influência sobre o desempenho financeiro de empresas industriais e comerciais. Com o seu desenvolvimento, em conjunto com o advento da Tecnologia da Informação - TI, dentre outros fatores, surge a possibilidade de uma cadeia de suprimentos gerenciada, ou como é chamada no contexto atual, Supply Chain Management - SCM.

Um dos problemas estudados e enfrentados por uma $S C M$ é o efeito chicote. Esse efeito é a variação ou a impossibilidade de alinhamento da demanda à oferta. Ballou (1993, p. xx) já afirmava que o grande desafio da logística é diminuir o hiato existente entre a produção e a demanda, de modo que os consumidores tenham bens e serviços quando e onde eles quiserem, e na condição física que desejarem.

Em outras palavras, o efeito chicote é o resultado de uma expectativa de demanda ou oferta que não se realiza, por diversos motivos, entre elas a incapacidade de prever a demanda dos clientes, e que se propaga por todas as empresas da cadeia, influenciando os níveis de estoques, os tamanhos dos pedidos e a produtividade.

Conhecido na literatura internacional como Bullwhip Efect, foi inicialmente apresentado por Forrester (1958).
Apesar de o nome utilizado não ter sido o mesmo, a situação era semelhante e até considerada normal para os gestores da época.

Para que seja possível alcançar alta eficiência na cadeia de suprimentos é necessário que sejam identificadas as forças e fatores que modelam o comportamento das empresas e suas interações com os participantes de sua cadeia. Uma vez modelado o sistema empresarial, é possível simular diversas situações e entender as circunstâncias que levam a um bom ou a um mau resultado.

Com base nisso, o objetivo deste artigo é, através da simulação de uma cadeia de suprimentos, mostrar a importância do compartilhamento de dados em cadeias de suprimentos como antídoto para as consequências do efeito chicote. Através da análise desses dados propõe-se um indicador para tornar possível a visualização dos níveis da propagação do efeito chicote na cadeia de suprimentos. Para isso, inicialmente, será apresentado um cenário onde os componentes de uma cadeia procuram alinhar sua oferta à demanda. E no final são apresentados os resultados gerados através da avaliação dos resultados de um simulador, que comprovam a necessidade de comunicação entre os elos de uma cadeia. 


\section{Metodologia}

Este artigo apresenta o método de trabalho de natureza aplicada, pois, segundo Silva e Menezes (2001), objetiva gerar conhecimentos para aplicação, abordando os problemas de forma quantitativa, dado que classifica e traduz em números as diferentes informações para sua posterior análise.

Do ponto de vista dos objetivos, segundo a classificação de Gil (1999), é considerada uma pesquisa exploratória visando aumentar o conhecimento acerca do problema pesquisado, assumindo as formas de pesquisa bibliográfica e estudo de caso, voltados à solução de problemas específicos. De acordo com Eisenhardt (1989), o estudo de caso é uma metodologia de pesquisa que visa a compreensão da dinâmica do caso em estudo. Eisenhardt (1989) afirma que esse método combina métodos de coleta de dados como documentos e observações, podendo a evidência ser qualitativa, quantitativa ou ambas; no caso deste trabalho esse método é quantitativo e, segundo Mattar (1999), apresenta dados originários na maioria das vezes de escalas numéricas, sendo então submetidos a análises estatísticas formais. O estudo de caso é usado para fornecer descrição, testar teoria ou gerar teoria, sendo neste artigo utilizado para ilustrar o efeito chicote, bem como testar o uso do indicador.

Dentre os pontos fortes são ressaltados aspectos como a geração de teoria nova, a possibilidade de se testar conceitos e hipóteses. Ainda segundo Eisenhardt (1989), a utilização de estudos de caso é apropriada quando a pesquisa encontra-se em estágio inicial ou quando se deseja fornecer uma nova perspectiva sobre um tema já discutido. $\mathrm{O}$ uso desse método se justifica pelos seguintes motivos:

- interpretação do Índice de Efeito Chicote (IEC) proposto, de forma a identificar em qual situação (excesso de demanda ou excesso de estoque) encontra-se a empresa estudada; e

- visualização gráfica da situação presente na cadeia de suprimentos, através de gráficos boxplot, para comparação entre antes e depois do compartilhamento de informações como proposta para diminuição do efeito chicote.

Do ponto de vista dos procedimentos técnicos adotados foram utilizados materiais já publicados (essencialmente livros e artigos de periódicos), constituindo assim uma pesquisa bibliográfica e de estudo de caso (GIL, 1999; SILVA; MENEZES, 2001).

\section{3 o efeito chicote}

Pode-se afirmar que o efeito chicote é resultado da discrepância entre a demanda real e a prevista, unida à intenção das empresas alinharem sua oferta a essa demanda, sem deixar de atendê-la. Dessa forma, as empresas, por não possuírem a informação correta de seus clientes, buscam se proteger e garantir o estoque para uma possível variação nessa demanda.

São inúmeras as pesquisas nessa área, as mais antigas datando do meio do século passado. Forrester $(1958,1961)$ detectou amplificações na demanda causadas por falta de visibilidade, informações distorcidas e ajustes nos níveis de estoque, tendo sido o precursor dos estudos do que veio a ficar conhecido como efeito chicote.

Lee et al. (1997) definem o efeito chicote como o fenômeno que ocorre quando as ordens de compra para os fornecedores tendem a uma variância maior do que as vendas do elo mais próximo do consumidor, causando uma percepção de distorção na demanda, onde esta se propaga para os componentes superiores da cadeia de suprimentos com uma variação mais acentuada.

Porém, como a demanda prevista muitas vezes não se concretiza, as organizações acabam com excesso de produtos em estoque, o que as leva, por exemplo, a reduzir suas compras. Ou, numa situação de falta de estoques, as empresas passariam a aumentar seus pedidos, criando nos fornecedores uma falsa impressão de alta demanda (o mesmo ajuste de estoques já detectado por Forrester em 1961). Independente da situação, esse reflexo vai sendo passado de cliente para fornecedor, até o final da cadeia, estabelecendo o efeito chicote.

Lee at al. (2004) perceberam, em pesquisa realizada juntamente com executivos da Procter e Gamble, que em um produto de pequena variação no consumo ocorria grande variação nos pedidos de seus clientes. Essa variação podia ser causada por vários fatores, mas logo constataram que não era devido à variação de consumo no mercado.

Svensson (2005) afirma que o efeito chicote indica que a variabilidade no nível de estoques tende a ser maior ao se afastar do ponto de consumo. Sendo que os fatores que o causam podem ser o compartilhamento de informações deficientes e dados de mercado insuficientes, que geram previsões incorretas.

Como forma de representar o efeito chicote, foi adaptado de Slack at al. (1999) o Quadro 1 - ele está dividido em dez períodos. Em cada um deles foi considerado que o mercado determinaria uma demanda real, então o varejista, com a política de equilibrar seu estoque com a demanda, compra o número de unidades que completam a demanda atual. E assim o distribuidor, a montadora e o fornecedor fazem o mesmo. Ou seja, todos mantêm em estoque uma quantidade igual à demanda do período. $\mathrm{O}$ estoque final do período de demanda é igual ao estoque inicial do período seguinte. Leva-se em consideração, ainda, que a compra feita é recebida no mesmo período.

A proposta desta representação é mostrar que uma pequena variação de demanda do mercado pode causar grande variação no fornecedor inicial. A idéia demonstrada é que o fornecedor sempre tentará equilibrar o estoque 
final do período com a demanda do mesmo período, pois não possui a informação do mercado, funcionando, assim, como uma espécie de previsão.

Logicamente, nas organizações existem mais fatores que atuam como restrições, que é o caso da capacidade de produção, que neste modelo foi considerada ilimitada ou suficiente para atender a demanda imediatamente, sem lead times. Como na grande maioria das empresas existe a sazonalidade, este modelo não a contemplou, aplicando-se uma variação máxima no consumo de $7 \%$ nos 10 períodos apresentados.

A Figura 1 é resultado dessa variação na demanda. Por exemplo, se for observada a coluna referente à demanda do mercado, no Quadro 1, é possível perceber que ela varia muito pouco. Porém, conforme os pedidos foram sendo efetuados entre as empresas, distanciando-se do ponto de consumo, a variação foi aumentando, o que representa o efeito chicote.

Segundo Warburton (2004), as ordens de compra dos vendedores para os seus fornecedores tendem a ter uma variação maior do que a demanda do consumidor que iniciou o processo, caracterizando o efeito chicote.

Em outras representações semelhantes a esta, observou-se o fato de que se acrescentados mais fatores, como os citados anteriormente, o efeito continua, porém os pontos de pico e declive se deslocam de suas posições. O que pode, por exemplo, dar a impressão de em alguns momentos a demanda estar em alta, mas a produção em baixa.

Acrescentando-se essas restrições, a variação e a incerteza aumentariam. Isso provavelmente causaria maiores impactos na cadeia, considerando que quanto mais distante a empresa estivesse do ponto de consumo, mais o efeito seria sentido. Ou seja, quanto mais distantes do consumidor final, mais propensas a manter estoques as empresas estariam, para serem capazes de absorver essas variações significativas (LIN, C.; LIN, Y. T., 2006).

Tendo em vista a quantidade de fatores que influenciam essa variação da demanda, torna-se útil elencar alguns dos diversos motivos de incertezas que levam as empresas a manter estoques. O Quadro 2, de Robenson et al. (1994) apud Dias (2003), apresenta os principais.

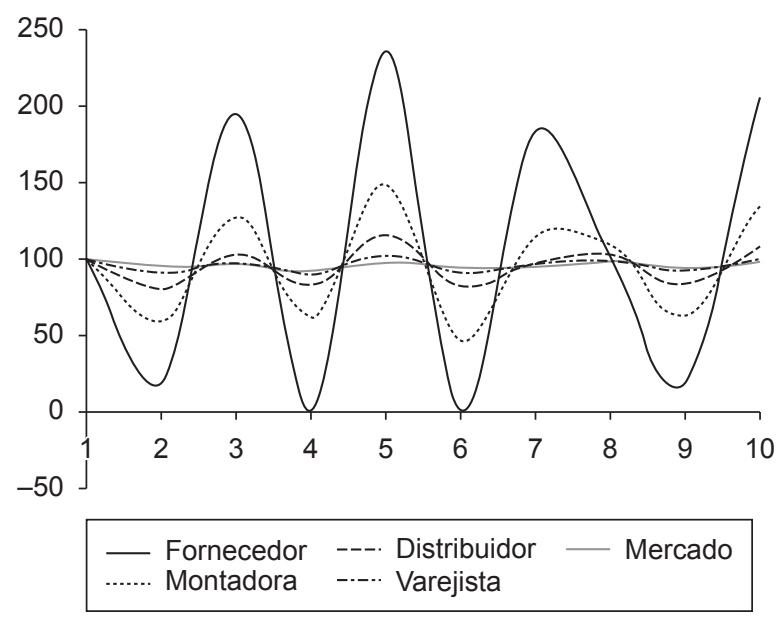

Figura 1. Ilustração gráfica do efeito chicote numa cadeia de abastecimentos fictícia. Fonte: Adaptado de Slack et al. (1999).

Quadro 1. Ilustração do efeito chicote numa rede de suprimentos fictícia.

\begin{tabular}{|c|c|c|c|c|c|c|c|c|c|c|c|c|c|}
\hline \multirow[t]{2}{*}{ Mês } & \multicolumn{3}{|c|}{ Fornecedor } & \multicolumn{3}{|c|}{ Montadora } & \multicolumn{3}{|c|}{ Distribuidor } & \multicolumn{3}{|c|}{ Varejista } & \multirow{2}{*}{$\begin{array}{l}\text { Mercado } \\
\text { Demanda }\end{array}$} \\
\hline & Produção & $\begin{array}{c}\text { E. } \\
\text { inicial }\end{array}$ & $\begin{array}{l}\text { E. } \\
\text { final }\end{array}$ & Produção & $\begin{array}{c}\text { E. } \\
\text { inicial }\end{array}$ & $\begin{array}{c}\text { E. } \\
\text { final }\end{array}$ & Compra & $\begin{array}{c}\text { E. } \\
\text { inicial }\end{array}$ & $\begin{array}{l}\text { E. } \\
\text { final }\end{array}$ & Compra & $\begin{array}{c}\text { E. } \\
\text { inicial }\end{array}$ & E. final & \\
\hline 1 & 100 & 100 & 100 & 100 & 100 & 100 & 100 & 100 & 100 & 100 & 100 & 100 & 100 \\
\hline 2 & 20 & 100 & 60 & 60 & 100 & 80 & 80 & 100 & 90 & 90 & 100 & 95 & 95 \\
\hline 3 & 196 & 60 & 128 & 128 & 80 & 104 & 104 & 90 & 97 & 97 & 95 & 96 & 96 \\
\hline 4 & 0 & 128 & 62 & 62 & 104 & 83 & 83 & 97 & 90 & 90 & 96 & 93 & 93 \\
\hline 5 & 236 & 62 & 149 & 149 & 83 & 116 & 116 & 90 & 103 & 103 & 93 & 98 & 98 \\
\hline 6 & 0 & 149 & 46 & 46 & 116 & 81 & 81 & 103 & 92 & 92 & 98 & 95 & 95 \\
\hline 7 & 184 & 46 & 115 & 115 & 81 & 98 & 98 & 92 & 95 & 95 & 95 & 95 & 95 \\
\hline 8 & 101 & 115 & 108 & 108 & 98 & 103 & 103 & 95 & 99 & 99 & 95 & 97 & 97 \\
\hline 9 & 18 & 108 & 63 & 63 & 103 & 83 & 83 & 99 & 91 & 91 & 97 & 94 & 94 \\
\hline 10 & 207 & 63 & 135 & 135 & 83 & 109 & 109 & 91 & 100 & 100 & 94 & 97 & 97 \\
\hline
\end{tabular}

Fonte: Adaptado de Slack et al. (1999). 
O desequilíbrio entre a expectativa de cada elemento da cadeia e o observado, percebido através dos níveis de estoques ao longo da cadeia de suprimentos, pode ser causado pelo método de agregação de valor nos diferentes processos de negócio das companhias (SVENSSON, 2005). Cabe ressaltar que todos os processos de uma empresa estão ligados ao fato da agregação de valor. Os que não estão encontram-se numa marcha muito forte de terceirização. O fato é que uma forma de se agregar valor ao produto é manter a sua disponibilidade - por exemplo, manter produtos em estoque ou nas prateleiras de um supermercado, como forma de garantir de que o cliente sempre encontrará os produtos desejados, quando quiser.

Porém, a disponibilidade de um produto tem um custo. De acordo com Ballou (1998), o custo de manutenção anual de estoques está entre 20 e $40 \%$ do custo do produto. Ou seja, é um valor extremamente alto e que pode ser revertido em lucros para as empresas.

Os custos de estocagem ocasionados pelo efeito, em determinados períodos, e a falta de estoques para atender a demanda, em outros, tendem a ser distribuídos por toda a cadeia, o que pode tornar o produto não competitivo. A visão de conjunto, de compartilhamento de informações, inerente ao conceito da $S C M$, é oportuna para a eliminação do efeito chicote. Mais detalhes serão vistos na seção a seguir.

Dentre várias ações possíveis, nesse sentido, são percebidas algumas com mais clareza. Por exemplo, as empresas têm procurado postergar ao máximo a sua compra. Porém, isso poderia causar a falta de mercadorias nas prateleiras, caso não houvesse uma aproximação, operacional e estratégica, maior entre cliente e fornecedor. Então, o que se vê não é tanto um problema de variação de demanda, mas de política de custos e redução dos níveis de estoques, relacionados à relação entre os membros da cadeia de abastecimento.

\section{As causas e propostas de solução}

Visto o alto custo incorrido para as empresas devido aos estoques, e sendo o efeito chicote um dos resultados da variação destes, busca-se identificar as causas desse efeito.

Forrester (1961) identificou lead times grandes como um dos principais motivos. Johnson (1998) apresenta como motivos a falta de compartilhamento de informação, alinhamento de decisões, redução do lead time e o uso de uma previsão comum para os membros da cadeia. Chen et al. (2000a; 2000b) defendem a centralização de informações. Lee et al. (2004) citam quatro causas principais para o efeito chicote:

- Processamento da previsão de demanda;

- Jogo da escassez ou racionamento;

- O tamanho dos pedidos; e

- Flutuações de preços.

Cada uma dessas causas tem o poder de alimentar o efeito chicote e pode atuar em efeito combinado, como explicado a seguir.

\subsection{Processamento da previsão de demanda}

A previsão da demanda é um fator fundamental para definição da estratégia de estocagem e de produção, esta mais importante para empresas industriais e a primeira para empresas de distribuição e comerciais. Assim, quanto mais precisos forem os dados, menor a possibilidade de erros na previsão e melhor o seu desempenho financeiro. É importante ressaltar que a precisão dos dados não elimina totalmente a probabilidade de falhas na previsão, dependendo também do tratamento destas, como será visto a seguir. Até porque não é possível prever com total precisão o comportamento humano, que é o que define, em última instância, o consumo.

Normalmente a coleta de dados pode acontecer de várias maneiras. Uma delas é trabalhar com base na demanda passada (métodos baseados em séries temporais). Outra pode ser através da tentativa de captar os sinais de demanda vindos do mercado (métodos causais) (COELHO, 2009).

Quadro 2. Forças que tornam os estoques necessários.

\begin{tabular}{|cc|}
\hline Motivo do estoque & Tipo de estoque \\
Incertezas & Estoque de segurança \\
Produção/Transporte em lotes & Estoque de ciclo \\
Tempo de transporte & Estoque em trânsito \\
Tempo de processamento & Estoque em processo \\
Sazonalidade & Estoques sazonais \\
Variação na taxa de atividades & Estoque de antecipação \\
Outros & Estoques especulativos \\
\hline
\end{tabular}

Fonte: Robenson et al. (1994) apud Dias (2003). 
Porém, o risco de utilizar qualquer um dos dois meios é muito grande, e é uma das causas fundamentais do desenvolvimento do efeito chicote na cadeia.

A única forma de conseguir precisão nesses dados é obtendo-os do ponto de consumo, ou que a previsão do cliente seja com base nesses dados. Porém, para que isso seja possível é necessário que exista um nível de informação e colaboração muito grande, além da confiança necessária entre os participantes da cadeia. Percebe-se que existem, aqui, aspectos ligados ao conceito de SCM.

Porém, segundo Lee at al. (2004), o simples fato de compartilhar a informação de demanda não é suficiente, pois cada componente da cadeia pode ter diferentes métodos de previsão. Essa diferença pode ser devido às estratégias da empresa e às técnicas de previsão, por exemplo. É preciso, então, que: ou todos pratiquem o mesmo modelo, ou que uma única empresa faça a previsão para todas as outras. Também há necessidade de uso de potentes softwares de gestão e compartilhamento de dados.

Lee at al. (2004) afirmam ainda que os lead time de pedidos longos contribuem para que ocorra o efeito chicote. Ou seja, é necessário então que esses ciclos de pedidos sejam reduzidos, de forma que o cliente possa se sentir mais seguro em relação à programação efetuada, evitando a sensação de falta de proteção quanto aos estoques.

\subsection{O jogo da escassez ou racionamento}

Se um varejista considerar a possibilidade de uma escassez nos produtos de determinada empresa, é muito provável que ele aumente a quantidade de seus pedidos, como forma de garantir para si uma boa parcela da produção do fabricante. Isso fará com que o fabricante necessite tomar cuidado no momento de fazer a alocação de sua produção.

Seja por necessidade ou por estratégia, o racionamento de produtos para o mercado influencia na maneira como as empresas efetuam o pedido. Por exemplo, se for percebida uma demanda superior à oferta é bem provável que as empresas se previnam, fazendo pedidos maiores. Esses pedidos serão atendidos e elevarão os estoques dos clientes, que por sua vez não farão novos pedidos. Desta forma a indústria, que desta vez está prevenida para uma alta demanda, ficará com seus estoques acima do estabelecido.

É importante, portanto, que o fabricante se previna desse jogo, alertando os clientes de uma ilusória falta de produtos. Para isso, é preciso que a informação sobre os níveis de produção e estocagem sejam compartilhados. Da mesma forma, que os clientes compartilhem sua previsão de demanda.

\subsection{O tamanho do pedido}

O tamanho do pedido é influenciado por dois fatores: o processo de revisão periódica do tamanho do lote e o alto custo de processamento de um pedido. O processo de revisão periódica pode ser melhorado com o acesso aos dados do ponto de venda. Devido à falta de certeza do que ocorre no final da cadeia, o fabricante, muitas vezes, acaba por revisar o tamanho do lote a ser produzido ou os produtos nele contidos. Com o compartilhamento é possível determinar uma agenda de produção coerente com as necessidades do mercado.

Já o alto custo de processamento de um pedido faz com que os fornecedores influenciem seus clientes a comprar lotes maiores e a reduzir o número de compras, o que traz bastante variação ao nível de produção, na ocorrência do pedido. Esse custo de processamento é formado principalmente pelo custo de transporte e pelo desconto dado pelo setor de vendas. Ou seja, um cliente que comprar uma carga completa ganha mais desconto do comercial e paga um valor menor no frete.

O que pode ser feito nesse caso é o uso de transportadoras de cargas fracionadas ou operadores logísticos que, por serem especializados no serviço de distribuição, podem trabalhar com custos menores. Desta forma o cliente não seria obrigado a comprar grandes lotes para ratear os custos de transporte.

Quanto ao desconto sobre vendas, normalmente relacionado ao volume do negócio, pode ser oferecido com base no histórico de compras, facilmente apurado com os softwares atualmente utilizados. Assim, o cliente pode continuar tendo direito aos mesmos descontos, com um custo de transporte também idêntico, mas com um nível de serviço superior. Os reflexos serão lotes menores, com o lote de produção sofrendo menos variações e a empresa se tornando mais sensível às informações recebidas dos clientes. Isso porque os lotes serão mais constantes, ao contrário do que eram antes.

\subsection{Flutuações de preços}

A política de preços utilizada por uma empresa influencia muito na forma como os clientes se comportam com relação aos pedidos. Se, por exemplo, existirem épocas em que ocorrem promoções, provavelmente a maioria dos pedidos será realizada nesse período. O que faz com que os estoques esvaziem e a produção fique com uma programação superior a sua capacidade, causando maiores custos de produção.

Uma solução seria o uso de uma política de preços baixos sempre, ao invés do uso de promoções. Essa proposta é baseada no fato de que, por mais que um preço baixo sempre possa reduzir os ganhos da empresa, ele a previne contra os custos oriundos da variação no tamanho dos lotes.

O Quadro 3 apresenta um resumo das quatro forças que causam o efeito chicote e a forma de agir sobre elas.

Tomando a proposta de Lee et al. (2004) como alicerce, pode-se propor um caminho para a solução de tudo isso, baseado em duas ações: compartilhar a informação e alinhar as estratégias. 
Estão disponíveis no mercado diversos sistemas capazes de gerenciar os dados necessários e convertê-los em informações para todos os componentes da cadeia de suprimentos, com segurança e agilidade. Quanto à estratégia, é necessário que as empresas pensem na cadeia como um todo, e para isso é necessário que a estratégia aponte para um objetivo em comum.

De forma geral, vários autores abordaram o assunto. Dias (2003) apresenta um resumo, conforme o Quadro 4, com a solução sugerida por três autores, entre eles Lee et al. (1997), abordado neste trabalho na versão de 2004.

Dias (2003) propõe três ações para a eliminação das causas do efeito chicote já identificadas. As três ações sugeridas no Quadro 4 estão baseadas na melhoria do processo logístico, compartilhamento de informações e redução do efeito de políticas comerciais. Pode-se considerar que essas ações são também necessárias para o bom funcionamento de uma SCM.

A cooperação e coordenação entre as operações das empresas são necessárias para evitar ou minimizar a variabilidade do nível de estoque nas cadeias de suprimentos (SVENSSON, 2005). Essa afirmação pode ser confirmada quando analisadas empresas montadoras de carros, por exemplo, onde estas e seus parceiros trabalham num modelo Supply Chain Management, o que contribui efetivamente para a redução dos níveis de estoques e a sua variabilidade, tornando o sistema mais ágil e flexível.

Assim como os quatro fatores apontados por Lee et al. (2004) são as causas principais para o efeito chicote, são neles que as empresas devem focar para que seja possível reduzi-lo. E isso pode ser feito através do compartilhamento de informações e alinhamento estratégico.

\section{Simulação da cadeia de suprimentos}

Analisa-se agora, com base numa simulação, se ao compartilhar a informação relacionada à demanda, a variabilidade, representada pelo efeito chicote, diminui na cadeia. Para isso verificou-se que é necessário desenvolver um índice que represente essa mudança. Ele deve mostrar se há variação entre a demanda e a produção e também deve servir de parâmetro para que seja possível verificar

Quadro 3. As causas e as medidas de contenção para o efeito chicote.

\begin{tabular}{|c|c|c|}
\hline Causas & Fatores que contribuem & Medidas de contenção \\
\hline $\begin{array}{l}\text { Processamento da previsão } \\
\text { de demanda }\end{array}$ & $\begin{array}{l}\text { Falta de visibilidade da demanda final; } \\
\text { Múltiplas previsões; } \\
\text { Ciclos de pedidos longos. }\end{array}$ & $\begin{array}{l}\text { Ter acesso a demanda final verdadeira; } \\
\text { Planejamento único; } \\
\text { Redução do tempo de ciclo de atendimento. }\end{array}$ \\
\hline O jogo da escassez & $\begin{array}{l}\text { Forma de racionamento proporcional; } \\
\text { Ignorar as condições de suprimento; } \\
\text { Pedidos irrestritos sem restrições de } \\
\text { devolução. }\end{array}$ & $\begin{array}{l}\text { Dividir a produção com base no histórico de vendas; } \\
\text { Compartilhamento de informações sobre capacidade e } \\
\text { suprimentos; } \\
\text { Limitar a flexibilidade a partir de um determinado prazo, e } \\
\text { reservar capacidade. }\end{array}$ \\
\hline O tamanho do pedido & $\begin{array}{l}\text { Alto custo de pedido; } \\
\text { Economia de escala (cargas fechadas). }\end{array}$ & $\begin{array}{l}\text { Uso de TI; } \\
\text { Concessão dos mesmos descontos das cargas fechadas }\end{array}$ \\
\hline Flutuações de preços & $\begin{array}{l}\text { Alta e baixa de preços; } \\
\text { Distribuição e compras não } \\
\text { sincronizadas. }\end{array}$ & $\begin{array}{l}\text { Preço baixo todo dia; } \\
\text { Contratos de fornecimento. }\end{array}$ \\
\hline
\end{tabular}

Fonte: Adaptado de Lee et al. (2004).

Quadro 4. Indicações para redução do efeito chicote.

\begin{tabular}{|llll|}
\hline \multicolumn{1}{|c|}{ Forrester (1958) } & \multicolumn{1}{c|}{ Lee et al. (1997) } & \multicolumn{1}{c|}{ Simchi-Levi et al. (2000) } \\
Melhoria do processo logístico & $\begin{array}{l}\text { Agilização do tratamento dos } \\
\text { pedidos }\end{array}$ & $\begin{array}{l}\text { Formação de lotes de compra } \\
\text { e de produção }\end{array}$ & $\begin{array}{l}\text { Redução do tempo de } \\
\text { ressuprimento }\end{array}$ \\
$\begin{array}{l}\text { Compartilhamento de } \\
\text { informações }\end{array}$ & $\begin{array}{l}\text { Melhoria na qualidade dos } \\
\text { dados } \\
\text { Ajuste dos estoques }\end{array}$ & $\begin{array}{l}\text { Processamento das variações } \\
\text { na demanda }\end{array}$ & $\begin{array}{l}\text { Formação de parcerias } \\
\text { estratégicas } \\
\text { Redução da incerteza }\end{array}$ \\
$\begin{array}{l}\text { Redução do efeito de políticas } \\
\text { comerciais }\end{array}$ & & Variações de preço & Redução da variabilidade \\
\hline
\end{tabular}

Fonte: Dias (2003). 
se em determinados elos o efeito chicote é maior do que em outros.

O índice desenvolvido é conseguido a partir da relação entre a produção efetiva de cada elo e sua demanda efetiva. Ou seja, a produção efetiva é o que cada elo tornou disponível para que seja vendido, enquanto que a demanda efetiva é o que o seu cliente comprou. Utiliza-se o termo "efetivo" devido ao fato de ser possível considerar a previsão de demanda ou planejamento de produção ou compras, conforme mencionado nos capítulos anteriores (Equação 1).

$$
I E C=\frac{D E}{P E}
$$

em que:

IEC - Índice do Efeito Chicote;

DE - Demanda Efetiva; e

PE - Produção Efetiva.

Uma cadeia de suprimentos sem ou com pouco efeito chicote é aquela em que o IEC é 1,00 ou muito próximo disso. Se o índice for maior que 1,00 , mostra que houve mais demanda do que produtos fabricados, tendo faltado mercadoria. Se o índice estiver menor do que a unidade, indica que houve produção acima do requerido pelo mercado, criando estoques em excesso, algo não desejado nas empresas atualmente. Com esse número pretende-se medir o quanto a produção se afasta da demanda conforme o elo se distancia do mercado consumidor.

Para dar base a este cálculo foi utilizado um simulador. Criado pelo Grupo de Estudos Logísticos (GELOG), do Departamento de Engenharia de Produção e Sistemas da Universidade Federal de Santa Catarina, ele possibilita representar o fluxo de materiais e informações resultante da interação entre as empresas clientes e fornecedoras.

O objetivo do simulador é representar uma cadeia de suprimentos no ramo têxtil, onde são produzidas calças. Essa cadeia é composta, basicamente, pelos elos apresentados na Figura 2.

A simulação foi realizada pelo GELOG com mais de 25 grupos de acadêmicos e profissionais. Os grupos eram divididos em quatro equipes, onde cada uma assumia um dos elos da cadeia. Cada equipe jogava dentro de dois diferentes contextos. No primeiro caso, o único elo com informação da demanda do "Varejo" era a "Fábrica de Acabamento". Dessa forma o pedido realizado por esse elo era o que definia a demanda para o seu fornecedor, a "Fábrica de Corte/Costura" e assim sucessivamente. No segundo contexto todos os componentes possuíam a informação da demanda prevista para o varejo.

Os pedidos não entregues em uma rodada acumulavam para a seguinte. Uma vez que exista estoque disponível, o envio é feito, não sendo possível reter produtos e não atender à demanda. Outras situações relacionadas à gestão ou à política de estoques ficaram a critério de cada equipe.

Os valores obtidos em todas as simulações encontram-se listados no Anexo A.

Com base nos conceitos e soluções apresentados nos capítulos anteriores, na simulação acima, conforme a informação da demanda estiver sendo transferida para os elos mais distantes do mercado, maior deverá ser o impacto do efeito chicote. Isso realmente ocorreu, e pode ser observado no Quadro 5.

A leitura do quadro deve ser feita da direita para esquerda, seguindo a mesma direção da cadeia, representada pela Figura 2. Percebe-se que o Acabamento, primeiro elo após o Varejo, teve uma variação com pico de 2,65 e mínimo de 0,68 num contexto em que não havia informação sobre a demanda do Varejo. Quando houve disponibilidade de informação da demanda do mercado consumidor, esses números mudaram para 1,54 e 0,74 respectivamente, mostrando-se mais próximos de 1,00 , indicando menor presença do efeito chicote.

Esse elo está informado sobre a demanda do Varejo. Porém, o que o impede de ter melhores desempenhos é o fato de a cadeia não estar conseguindo atender a sua necessidade, pois as estratégias de produção não estão alinhadas. Assim, mesmo com a informação disponível, no primeiro contexto, ele depende de uma cadeia que não dispõe das mesmas condições.

O elo de Corte/Costura sofreu uma variação maior. Chegou, no caso da não existência de informação, a 4,29 de máximo e 0,50 de mínimo. Os indicadores melhoraram

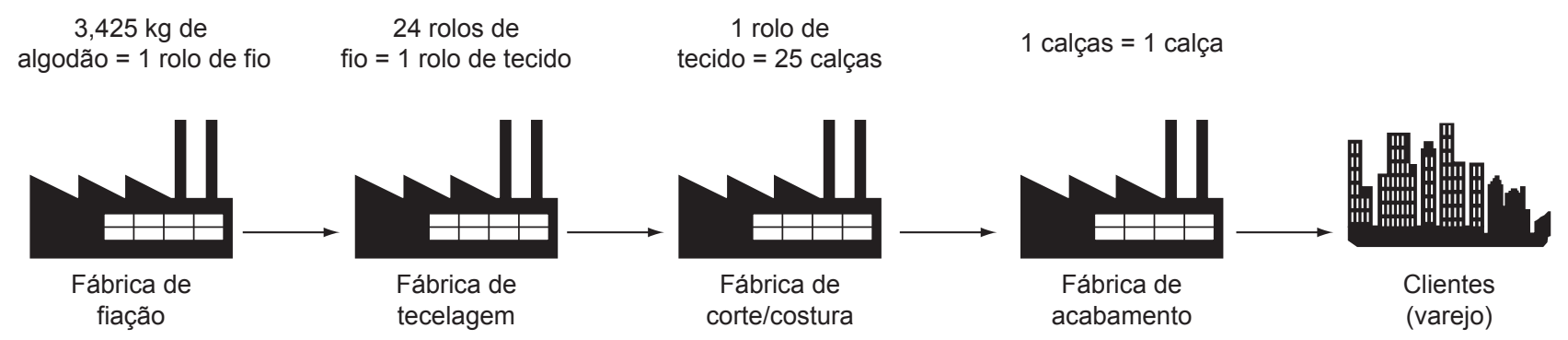

Figura 2. Representação da cadeia de suprimentos da indústria de calças. Fonte: Grupo (2007). 
Quadro 5. Comportamento do IEC conforme se afastava do varejo.

\begin{tabular}{|ccccccccccc}
\hline & \multicolumn{2}{c}{ Fiação } & \multicolumn{2}{c}{ Tecelagem } & \multicolumn{2}{c|}{ Corte/Costura } & \multicolumn{2}{c|}{ Acabamento } \\
& Mínimo & Máximo & Mínimo & Máximo & Mínimo & Máximo & Mínimo & Máximo \\
Sem informação & 0,27 & 3,58 & 0,15 & 4,00 & 0,50 & 4,29 & 0,68 & 2,65 \\
Com informação & 0,31 & 2,82 & 0,37 & 3,50 & 0,77 & 1,64 & 0,74 & 1,54 \\
\hline
\end{tabular}

significativamente quando houve compartilhamento da informação: 1,64 de máximo e 0,77 de mínimo. Com esses índices pode-se dizer que no caso de um IEC de 4,29 a empresa fornecedora conseguiu somente atender a $25 \%$ da demanda, ou seja, para cada 4,29 itens que o mercado necessitava no período foi the fornecido apenas 1 . E isso melhorou significativamente quando a informação foi compartilhada, pois o desequilíbrio se reduziu a um IEC de 1,64 .

O mesmo raciocínio deve ser aplicado aos elos da Tecelagem e Fiação. Mas merece destaque o fato de que os valores máximos e mínimos tendem a ser mais díspares de 1,00 à medida que o elo está mais distante do mercado consumidor, como se estudou nas seções anteriores.

Para ajudar na visualização do Quadro 5, optou-se por construir os gráficos boxplot para cada elo. O gráfico boxplot pode ser usado para comparar distribuições de dados que, nesse caso, contribuem para a visualização dos extremos. Ou seja, irá representar como esses dados se comportam em relação ao índice desejado - 1,00.

O conjunto de gráficos para todos os elos está mostrado na Figura 3. São comparados os elos nas etapas em que não houve compartilhamento de informação e depois naquela em que houve tal compartilhamento.

As linhas horizontais indicam:

- linha horizontal mais baixa: $1^{\circ}$ quartil (Q1) - $25 \%$ dos dados estão abaixo desta linha ou são iguais a ela;

- linha horizontal do meio: mediana - metade das observações está abaixo desta linha ou são iguais a ela;

- linha horizontal superior: $3^{\circ}$ quartil (Q3) - 75\% dos dados estão abaixo desta linha ou são iguais a ela.

As linhas verticais indicarão os valores máximos e mínimos, desde que dentro do intervalo Q3 + 1,5(Q3-Q1) para o limite superior e Q1 - 1,5(Q3-Q1) para os limites superior e inferior, respectivamente. Os gráficos individuais estão mostrados na Figura 3 abaixo.

Os asteriscos num gráfico boxplot indicam outliers, ou dados fora dos padrões estatísticos, pontos extremos, além dos limites calculados anteriormente para as linhas verticais.

Ficam evidentes duas constatações, já esperadas, se observada a teoria apresentada:
- A segunda etapa, referente àquela em que há compartilhamento da informação sobre a demanda, teve, em todos os elos, valores melhores do índice, ou seja, os valores são menos distantes de 1,00, apesar de o elo Tecelagem ter apresentado uma melhoria menor que a dos outros elementos;

- Os elos mais próximos do mercado consumidor, como a Fábrica de Acabamento dessa simulação, apresentaram menor variação, tendo seus valores extremos mais próximos da unidade do que os elos mais afastados do mercado, Fiação e Tecelagem nesse caso.

Dessa forma, embora a simulação não represente todas as restrições de uma cadeia de suprimentos real, a interação entre os participantes e a necessidade de compartilhar informação, como forma de diminuir a presença do efeito chicote, se mostraram condizentes com a bibliografia apresentada. É, portanto, necessário que se estudem formas de melhorar essa troca de informações, pois, como também pôde ser visto, a simples comunicação entre os participantes não elimina completamente o efeito.

\section{Conclusão}

O compartilhamento de informações, como foi proposto, pode reduzir o impacto do efeito chicote, o que foi possível visualizar através do IEC. É perceptível, porém, que somente o compartilhamento, puro e simples como realizado na simulação, não é suficiente, pois ainda restam muitas discrepâncias em termos de demanda e oferta. O resultado seria, portanto, mais efetivo se a troca de dados estivesse alinhada com as estratégias das empresas e de toda cadeia. Ou seja, mais do que trocar dados sobre números de itens vendidos, trocar também informações estratégicas.

O alinhamento das estratégias, com base na percepção de valor do cliente, faz-se necessário, uma vez que ele possibilitará o uso da própria TI, que pode tornar o compartilhamento de informações mais eficaz. Essa atitude só se torna viável se a governança da cadeia de abastecimento se mostrar forte o suficiente para alinhar as percepções de todos os seus atores para o mesmo objetivo.

É, portanto, visível que o problema do efeito chicote não será sanado com uma única ação. $\mathrm{O}$ desenvolvimento 

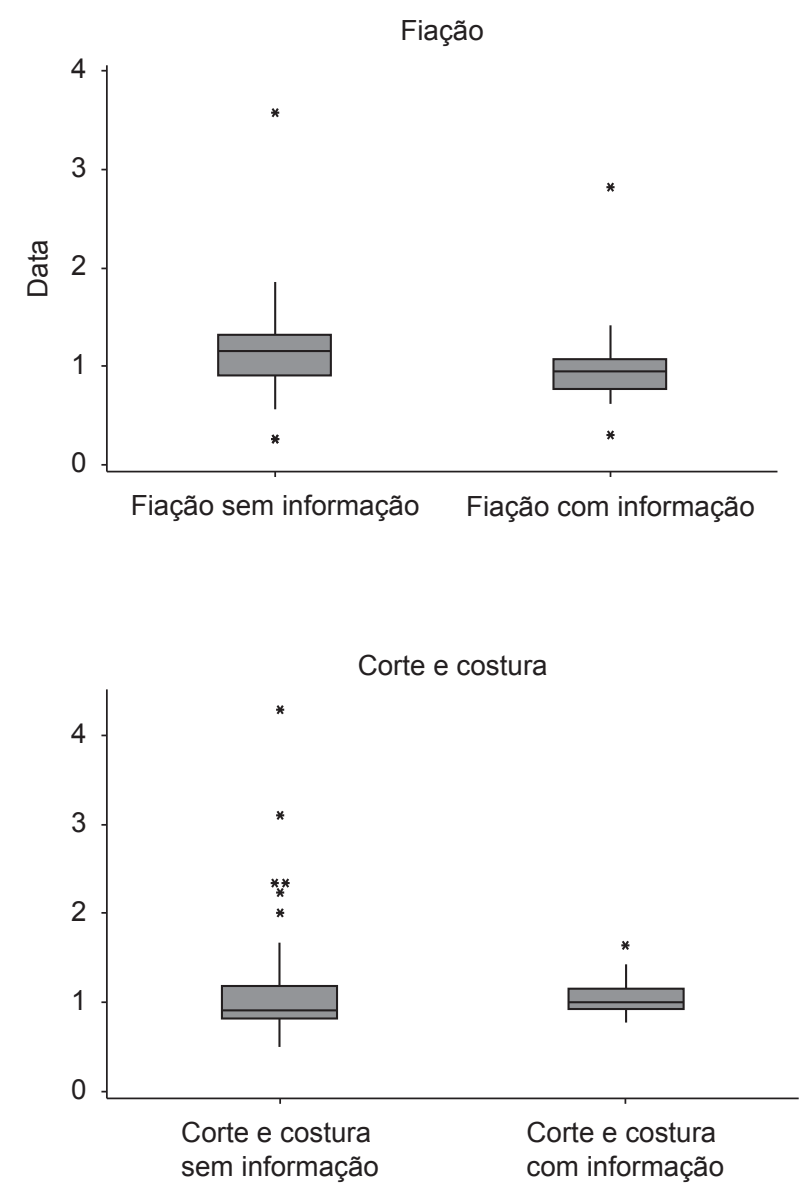

Tecelagem
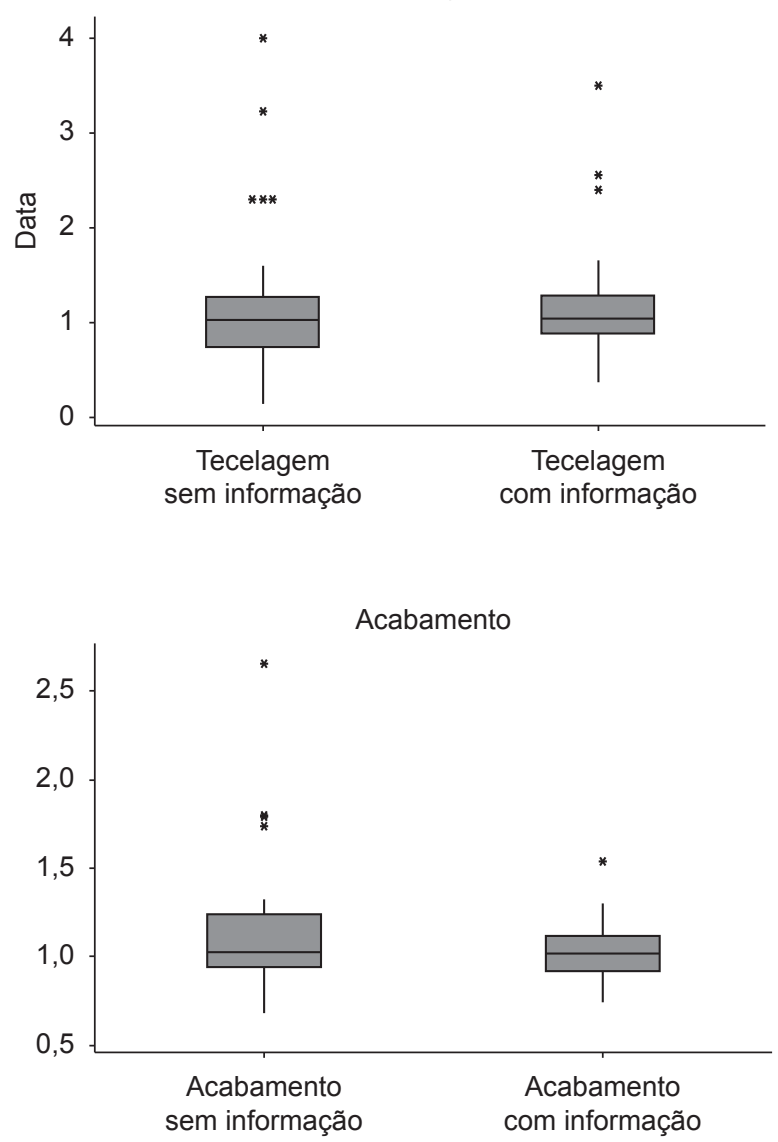

Figura 3. Gráficos boxplot para os elos da cadeia, com e sem informação compartilhada de demanda (note que a escala do elo Acabamento é maior para facilitar a correta visualização dos dados). Fonte: Própria.

de competências por todos os elos da cadeia é que irá desencadear o sucesso sinérgico. É necessário que todos estejam comprometidos em compartilhar informações, dispostos a gerenciar e serem gerenciados, dentro do conceito de $S C M$.

Fala-se isso porque é comum a insegurança de se passar uma informação para um fornecedor que pode ser, também, o fornecedor de um concorrente. Visa-se um ideal, que para algumas empresas pode estar mais próximo do que para outras, e que precisa ser almejado, planejado e posto em prática para que seja alcançado.

Percebe-se que as ações relacionadas à gestão da cadeia de abastecimento têm servido como antídoto para muitos paradigmas existentes nas empresas. Nesse caso específico, em que foi tratado sobre o efeito chicote, identificadas suas causas e propostas as possíveis soluções, pôde ser visto que a integração entre empresas fornecedoras e clientes, até os extremos da cadeia, pode ser útil e necessária.

Sabendo-se que o efeito chicote é uma representação real da variabilidade no tamanho dos pedidos e, consequentemente, tem forte influência nos níveis de estoques e na capacidade de produção das indústrias, é necessário que se olhe as estratégias ligadas à gestão desses fluxos. $\mathrm{Ou}$ seja, sabendo-se que não se pode eliminar o efeito chicote somente com o compartilhamento das informações e que é possível que o entendimento da estratégia dos parceiros possa contribuir para tal, deve-se considerar o fato da integração estratégica das empresas como necessário. 


\title{
The bullwhip effect in the supply chain - indicator proposal
}

\begin{abstract}
The objective of this paper is to emphasize the importance of sharing data in a supply chain, as a strategy to reduce the bullwhip effect. To achieve this effect, its causes, the ways it shows itself and the means to avoid it are presented. In order to facilitate the understanding about the damages caused by its influence, a hypothetical scenario is suggested, in which the components of a supply chain try to align its offer to its demand. Next, based on a bibliographical research, the solution - the strategic alignment and the information sharing - are shown, thus creating the synergy needed for developing competitive advantage for the company and/or for the chain. Finally, to support this solution, we created an indicator based on a supply chain, simulated several times in the classroom using software, which demonstrated the positive effects of sharing data.
\end{abstract}

Keywords: Bullwhip effect. Supply chain management. Competitive advantage. Bullwhip effect indicator.

\section{Referências bibliográficas}

BALLOU, R. H. Logística empresarial. São Paulo: Editora Atlas, 1993.

BALLOU, R. H. Business logistics management: planning, organizing, and controlling the supply chain. 4 ed. Londes: Prentice Hall, 1998.

CHEN, F. et al. Quantifying the bullwhip effect in a simple supply chain: the impact of forecasting, lead time, and information. Manage Science, v. 46, n. 3, p. 436-443, 2000a.

CHEN, F.; RYAN, J. K.; SIMCHI-LEVI, D. The impact of exponential smoothing forecasts on the bullwhip effect. Naval Research Logistics (NRL), v. 47, n. 4, p. 269-286, 2000b.

COELHO, L. C. Logística e previsão de demanda: uma questão de controle de estoques. 2009. Disponível em: <http://inbrasc.org.br/ itemBiblioteca. aspx?id=581>. Acesso em: 15 Outubro 2009.

DIAS, G. P. P. Gestão dos estoques numa cadeia de distribuição com sistema de reposição automática e ambiente colaborativo. São Paulo, 2003. Dissertação (Mestrado) - Escola Politécnica, Universidade de São Paulo - USP.

EISENHARDT, K. M. Building theories from case study research. Academy of Management Review, v. 14, n. 4, p. 532-550, 1989.

FORRESTER, J. Industrial Dynamics. New York: MIT Press e John Wiley \& Sons, Inc., 1961.

FORRESTER, J. Industrial Dynamics. Harvard Business Review, n. 36, Julho - Agosto 1958.

GRUPO de Estudos Logísticos - GELOG. Santa Catarina: Departamento de Engenharia de Produção e Sistemas, Universidade
Federal de Santa Catarina, 2007. Disponível em: <http://www. gelog.ufsc.br/joomla/>.

GIL, A. C. Métodos e Técnicas de pesquisa social. 5 ed. São Paulo: Atlas, 1999.

JOHNSON, M. E. Giving them what they want. Management Review, v. 87, n. 10, p. 62-67, 1998.

LEE, H. L.; PADMANABHAN, V.; WHANG, S. Information distortion in a supply chain: the bullwhip effect. Management Science, v. 43, n. 4, p. 546-558, 1997.

LEE, H. L.; PADMANABHAN, V.; WHANG, S. Information distortion in a supply chain: the bullwhip effect. Management Science, v. 50, n. 12, Dezembro 2004.

LIN, C.; LIN, Y. T. Mitigating the bullwhip effect by reducing demand variance in the supply chain. International Journal of Advanced Manufactoring Technology, v. 28, p. 328-336, 2006.

MATTAR, F. N. Pesquisa de marketing: metodologia, planejamento. 5 ed. São Paulo: Atlas, 1999.

SILVA, E. L.; MENEZES, E. S. Metodologia da pesquisa e elaboração de dissertação. 3 ed. Florianópolis, 2001.

SLACK, N. et al. Administração da Produção. São Paulo: Atlas, 1999

SVENSSON, G. The multiple facets of the bullwhip effect: refined and re-defined. International Journal of Physical Distribution \& Logistics Management, n. 35, Setembro/Outubro 2005.

WARBURTON, R. D. H. An analytical investigation of the bullwhip effect. Production and Operations Management, v. 13, n. 2, p. 150-160, 2004. 


\section{Sobre os autores}

\section{Leandro Callegari Coelho}

Centre Interuniversitaire de Recherche sur les Réseaux d'Entreprise, la Logistique et le Transport - CIRRELT, HEC Montréal Montréal - QC, Canadá

e-mail: leandrocc@gmail.com

\section{Neimar Follmann}

Programa de Pós-Graduação em Engenharia de Produção, Departamento de Engenharia de Produção e Sistemas, Campus Universitário Universidade Federal de Santa Catarina - UFSC

Florianópolis - SC, Brasil

e-mail: neimarfollmann@gmail.com

\section{Carlos Manuel Taboada Rodriguez}

Programa de Pós-Graduação em Engenharia de Produção, Departamento de Engenharia de Produção e Sistemas, Campus Universitário Universidade Federal de Santa Catarina - UFSC

Florianópolis - SC, Brasil

e-mail: taboada@deps.ufsc.br

Agradecimentos: Os autores Leandro Callegari Coelho e Neimar Follmann agradecem ao Conselho Nacional de Pesquisa (CNPq) pela bolsa de mestrado concedida durante parte da realização deste trabalho. O autor Neimar Follmann agradece ao CNPq pela bolsa de doutorado concedida durante parte da realização deste trabalho. O autor Leandro Callegari Coelho agradece à HEC Montréal pelo apoio financeiro concedido.

Recebido em 24/11/2008 Aceito em 16/11/2009 


\section{Anexo A - Valores de cada elo nas simulações da Cadeia de Suprimentos têxtil}

\begin{tabular}{|c|c|c|c|c|c|c|c|}
\hline \multicolumn{4}{|c|}{ Elo: acabamento } & \multicolumn{4}{|c|}{ Elo: corte e costura } \\
\hline \multicolumn{2}{|c|}{$\begin{array}{c}\text { Sem compartilhamento } \\
\text { de informações }\end{array}$} & \multicolumn{2}{|c|}{$\begin{array}{c}\text { Com compartilhamento } \\
\text { de informações }\end{array}$} & \multicolumn{2}{|c|}{$\begin{array}{l}\text { Sem compartilhamento } \\
\text { de informações }\end{array}$} & \multicolumn{2}{|c|}{$\begin{array}{c}\text { Com compartilhamento } \\
\text { de informações }\end{array}$} \\
\hline $\begin{array}{c}\text { Demanda } \\
\text { efetiva }\end{array}$ & $\begin{array}{c}\text { Produção } \\
\text { efetiva }\end{array}$ & $\begin{array}{c}\text { Demanda } \\
\text { efetiva }\end{array}$ & $\begin{array}{c}\text { Produção } \\
\text { efetiva }\end{array}$ & $\begin{array}{c}\text { Demanda } \\
\text { efetiva }\end{array}$ & $\begin{array}{c}\text { Produção } \\
\text { efetiva }\end{array}$ & $\begin{array}{c}\text { Demanda } \\
\text { efetiva }\end{array}$ & $\begin{array}{c}\text { Produção } \\
\text { efetiva }\end{array}$ \\
\hline 11719 & 11000 & 11392 & 12000 & 12000 & 13500 & 13000 & 14000 \\
\hline 13317 & 11000 & 12177 & 15000 & 12000 & 13500 & 15000 & 12500 \\
\hline 13108 & 11000 & 13661 & 11000 & 12000 & 13400 & 9500 & 10000 \\
\hline 10563 & 11000 & 10875 & 10500 & 12000 & 12500 & 11000 & 9000 \\
\hline 10791 & 11500 & 10191 & 11000 & 12000 & 14400 & 11000 & 14050 \\
\hline 15357 & 13550 & 14946 & 12750 & 15500 & 12500 & 12400 & 10000 \\
\hline 12590 & 4750 & 13007 & 13400 & 7000 & 14000 & 10350 & 9000 \\
\hline 9808 & 10780 & 9009 & 9800 & 14000 & 6000 & 9750 & 9000 \\
\hline 14060 & 10620 & 15400 & 10000 & 11000 & 12000 & 13785 & 13025 \\
\hline 13012 & 13000 & 10791 & 12400 & 7000 & 14000 & 13000 & 12886 \\
\hline 9808 & 10780 & 12614 & 11277 & 14000 & 6000 & 9372 & 12209 \\
\hline 14060 & 10620 & 12871 & 11823 & 11000 & 12000 & 7900 & 5518 \\
\hline 13012 & 13000 & 11001 & 10100 & 9000 & 13000 & 8000 & 7375 \\
\hline 9658 & 9400 & 14537 & 14770 & 6000 & 1400 & 13428 & 14400 \\
\hline 12798 & 13000 & 12590 & 14500 & 10000 & 12000 & 13474 & 13500 \\
\hline 12528 & 7000 & 10087 & 7800 & 10000 & 6000 & 10946 & 11000 \\
\hline 10910 & 14400 & 9881 & 10780 & 15400 & 14400 & 10946 & 8750 \\
\hline 12250 & 12500 & 13799 & 13886 & 15400 & 6875 & 14785 & 14400 \\
\hline 12765 & 7110 & 12367 & 12177 & 7000 & 6250 & 13163 & 13163 \\
\hline 9002 & 8915 & 10053 & 9868 & 10000 & 5000 & 10664 & 10650 \\
\hline 9481 & 9261 & 10987 & 12300 & 7500 & 14400 & 10664 & 12050 \\
\hline 14996 & 12639 & 13110 & 11600 & 13200 & 4250 & 13604 & 14000 \\
\hline 13494 & 12150 & 13677 & 13000 & 11000 & 13875 & 10500 & 13600 \\
\hline 10423 & 11000 & 9987 & 10104 & 9000 & 8500 & 8500 & 7500 \\
\hline 9843 & 14400 & 10200 & 13779 & 15400 & 14200 & 14000 & 14000 \\
\hline 13237 & 10000 & 14331 & 11030 & 9500 & 11650 & 9000 & 11500 \\
\hline 12601 & 10500 & 13508 & 12047 & 8000 & 9150 & 9000 & 5500 \\
\hline 9843 & 14400 & & & 15400 & 14200 & & \\
\hline 13237 & 10000 & & & 9500 & 11650 & & \\
\hline 12601 & 10500 & & & 8000 & 9150 & & \\
\hline 9842 & 12100 & & & 13000 & 13500 & & \\
\hline 13164 & 14200 & & & 12100 & 12500 & & \\
\hline 13539 & 7806 & & & 4386 & 7500 & & \\
\hline 9255 & 9780 & & & & & & \\
\hline
\end{tabular}


Anexo A. Continuação...

\begin{tabular}{|c|c|c|c|c|c|c|c|}
\hline \multicolumn{4}{|c|}{ Elo: fiação } & \multicolumn{4}{|c|}{ Elo: tecelagem } \\
\hline \multicolumn{2}{|c|}{$\begin{array}{c}\text { Sem compartilhamento } \\
\text { de informações }\end{array}$} & \multicolumn{2}{|c|}{$\begin{array}{c}\text { Com compartilhamento } \\
\text { de informações }\end{array}$} & \multicolumn{2}{|c|}{$\begin{array}{l}\text { Sem compartilhamento } \\
\text { de informações }\end{array}$} & \multicolumn{2}{|c|}{$\begin{array}{c}\text { Com compartilhamento } \\
\text { de informações }\end{array}$} \\
\hline $\begin{array}{c}\text { Demanda } \\
\text { efetiva }\end{array}$ & $\begin{array}{l}\text { Produção } \\
\text { efetiva }\end{array}$ & $\begin{array}{c}\text { Demanda } \\
\text { efetiva }\end{array}$ & $\begin{array}{c}\text { Produção } \\
\text { efetiva }\end{array}$ & $\begin{array}{c}\text { Demanda } \\
\text { efetiva }\end{array}$ & $\begin{array}{c}\text { Produção } \\
\text { efetiva }\end{array}$ & $\begin{array}{l}\text { Demanda } \\
\text { efetiva }\end{array}$ & $\begin{array}{c}\text { Produção } \\
\text { efetiva }\end{array}$ \\
\hline 12500 & 11500 & 8212 & 10004 & 520 & 500 & 550 & 492 \\
\hline 12500 & 11500 & 8918 & 10258 & 520 & 500 & 500 & 372 \\
\hline 12500 & 10764 & 12110 & 12110 & 520 & 492 & 450 & 416 \\
\hline 12500 & 10481 & 12800 & 9040 & 520 & 463 & 450 & 505 \\
\hline 13680 & 11100 & 2800 & 9128 & 500 & 567 & 500 & 530 \\
\hline 11040 & 11919 & 8000 & 12099 & 530 & 520 & 350 & 413 \\
\hline 4000 & 14800 & 8000 & 2233 & 174 & 460 & 300 & 117 \\
\hline 13820 & 7400 & 9500 & 12000 & 460 & 200 & 350 & 300 \\
\hline 13680 & 11100 & 6800 & 11000 & 530 & 520 & 521 & 500 \\
\hline 11040 & 11919 & 14165 & 14000 & 174 & 460 & 596 & 360 \\
\hline 4000 & 14800 & 9000 & 9000 & 460 & 200 & 548 & 386 \\
\hline 13820 & 7400 & 11000 & 13140 & 424 & 380 & 464 & 520 \\
\hline 12000 & 10000 & 13300 & 10360 & 310 & 468 & 406 & 330 \\
\hline 12000 & 4250 & 7400 & 10500 & 275 & 550 & 79 & 520 \\
\hline 7400 & 8000 & 10510 & 8509 & 575 & 250 & 350 & 100 \\
\hline 13200 & 9460 & 9750 & 9755 & 800 & 200 & 700 & 540 \\
\hline 6000 & 10639 & 13150 & 13133 & 1000 & 310 & 700 & 440 \\
\hline 4800 & 7400 & 13000 & 13144 & 600 & 545 & 500 & 410 \\
\hline 11350 & 10500 & 11190 & 10500 & 160 & 438 & 400 & 550 \\
\hline 13500 & 10000 & 10461 & 12811 & 450 & 280 & 527 & 527 \\
\hline 9800 & 5720 & 13085 & 11500 & 400 & 479 & 426 & 407 \\
\hline 7400 & 13080 & 13200 & 12000 & 550 & 430 & 507 & 500 \\
\hline 13625 & 10500 & 9720 & 12800 & 350 & 470 & 482 & 550 \\
\hline 9000 & 12519 & 10776 & 14800 & 550 & 430 & 540 & 547 \\
\hline 13000 & 14200 & 11270 & 11840 & 350 & 470 & 380 & 403 \\
\hline 13799 & 10000 & 7400 & 5920 & 530 & 565 & 350 & 400 \\
\hline 13625 & 10500 & 9000 & 12188 & 350 & 433 & 350 & 320 \\
\hline 9000 & 12519 & 11000 & 11701 & 308 & 554 & 500 & 492 \\
\hline 13000 & 14200 & 10500 & 12620 & & & 350 & 400 \\
\hline 13799 & 10000 & & & & & 300 & 440 \\
\hline 11800 & 9360 & & & & & 480 & 200 \\
\hline 12000 & 12440 & & & & & & \\
\hline 14800 & 12800 & & & & & & \\
\hline
\end{tabular}

Fonte: GELOG - Grupo de Estudos Logísticos (GRUPO, 2007). 